\title{
Erythropoietin-producing hepatocellular A6 overexpression is a novel biomarker of poor prognosis in patients with breast cancer
}

\author{
DANMEI ZHOU ${ }^{1 *}$, KEHAN REN $^{2 *}$, JIGANG WANG $^{2}$, HONG REN $^{1}$, WENLIN YANG ${ }^{2}$, \\ WENJUAN WANG ${ }^{1}$, QIONG LI ${ }^{1}$, XIUPING LIU ${ }^{3}$ and FENG TANG ${ }^{1}$ \\ ${ }^{1}$ Department of Pathology, Huashan Hospital Affiliated to Fudan University, Shanghai 200040; \\ ${ }^{2}$ Department of Pathology, School of Basic Medical Sciences, Fudan University, Shanghai 200030; \\ ${ }^{3}$ Department of Pathology, The Fifth People's Hospital of Shanghai, Fudan University, Shanghai 200240, P.R. China
}

Received February 5, 2016; Accepted December 15, 2017

DOI: 10.3892/ol.2018.7919

\begin{abstract}
Erythropoietin-producing hepatocellular A6 (EphA6) is a member of the Eph receptor tyrosine kinase family, which has been implicated in tumorigenesis. However, little is known about the expression and function of EphA6 in breast cancer. The aim of the present study was to investigate the expression of EphA6 and the possible association between EphA6 and clinicopathological characteristics in breast cancer. In the present study, EphA6 mRNA expression was measured in 26 paired breast cancer tissues and adjacent non-cancerous tissues by reverse transcription-quantitative polymerase chain reaction. Additionally, the protein expression of EphA6 in breast cancer tissues from 116 patients was examined by immunohistochemistry, and the prognostic value for patients with breast cancer was evaluated. The results of the present study indicated that EphA6 mRNA and protein expression in breast cancer was significantly higher than that in adjacent non-cancerous tissues $(\mathrm{P}<0.001)$. EphA6 overexpression was significantly associated with a high histological grade $(\mathrm{P}<0.001)$, overexpression of human epidermal growth factor 2 (HER-2; $\mathrm{P}=0.0106$ ), low estrogen receptor expression $(\mathrm{P}=0.0247)$ and low progesterone receptor expression $(\mathrm{P}=0.0015)$. Furthermore, the increased expression of EphA6 was demonstrated to be associated with breast cancer subtypes $(\mathrm{P}=0.0164)$. Kaplan-Meier curves
\end{abstract}

Correspondence to: Professor Feng Tang, Department of Pathology, Huashan Hospital Affiliated to Fudan University, 12 Middle Urumqi Road, Shanghai 200040, P.R. China

E-mail: tangfeng1966@sina.com

Professor Xiuping Liu, Department of Pathology, The Fifth People's Hospital of Shanghai, Fudan University, 128 Ruili Road, Shanghai 200240, P.R. China

E-mail: xpliu1228@fudan.edu.cn

${ }^{*}$ Contributed equally

Key words: erythropoietin-producing hepatocellular A6, breast cancer, estrogen receptor, progesterone receptor, human epidermal growth factor receptor 2, prognosis demonstrated that high EphA6 expression was associated with lower overall survival rates in patients with breast cancer $(\mathrm{P}=0.015)$. Univariate and multivariate analysis revealed that high EphA6 expression, Tumor-Node-Metastasis classification and subtype were independent prognostic factors for patients with breast cancer (all $\mathrm{P}<0.05$ ). In conclusion, EphA6 may serve an important role in breast carcinogenesis and may pose as a novel prognostic indicator and therapeutic target for breast cancer, particularly in patients with steroid receptor negative expression and HER-2 overexpression.

\section{Introduction}

In 2012, breast cancer was the most common cancer in females worldwide (1). It is estimated that 1.6 million new diagnoses of breast cancer and 1.2 million breast cancer-associated mortalities occur in China every year (2). Surgery is the primary treatment for localized breast cancer, while adjunctive therapies, including radiotherapy, chemotherapy, hormonal therapy and targeted therapy may also improve the survival rate of patients (3-5). However, delayed diagnosis, recurrence and acquiring resistance remain obstacles to the successful treatment of breast cancer. Therefore, the identification of associated detection biomarkers and therapeutic targets is essential for the accurate and sensitive diagnosis and prognosis of breast cancer.

Erythropoietin-producing hepatocellular (Eph) receptors belong to the tyrosine kinase receptor family, which was first identified as being involved in the tumorigenic process 3 decades ago (6). In the human genome, there are 9 EphA receptors and $5 \mathrm{EphB}$ receptors, which serve key roles in normal physiology, including cell migration, cell adhesion, cell proliferation and cell-fate determination. These activities depend on the binding of their Eph receptor-interacting (ephrin) proteins, of which there are 8 members. Compelling evidence has demonstrated that Eph receptors and ephrins affect tumor growth, invasiveness, angiogenesis and metastasis (7-9). EphA6, an EphA receptor, was previously identified to serve a critical role in carcinogenesis, but its role in cancer progression has only been studied in prostate cancer (10). Therefore, the expression level and clinical significance of EphA6 in breast cancer remains unclear. 
In the present study, the mRNA expression of EphA6 in paired breast cancer and adjacent non-cancerous tissues was investigated using reverse transcription-quantitative polymerase chain reaction (RT-qPCR). Additionally, the protein expression of EphA6 in 116 patients with breast cancer was analyzed by immunohistochemistry (IHC) and the association between EphA6 expression and clinicopathological parameters was examined. The outcome of patients was used to determine whether EphA6 may be used as a diagnostic and prognostic marker for breast cancer.

\section{Materials and methods}

Patients and tissue samples. All tissue samples were collected from Huashan Hospital Affiliated to Fudan University (Shanghai, China). Paired breast cancer samples and adjacent non-cancerous tissues $(\geq 5 \mathrm{~cm}$ from the tumor edge) were collected from 26 patients who had undergone mastectomy at Huashan Hospital between January 2011 and July 2012 . The samples were immediately stored at $-80^{\circ} \mathrm{C}$ prior to total RNA extraction. For immunohistochemical assays, 116 formalin-fixed, paraffin-embedded (FFPE) breast cancer tissues, fixed in $4 \%$ formaldehyde, for $24-48 \mathrm{~h}$ at room temperature, were obtained from the Department of Pathology (Huashan Hospital Affiliated to Fudan University, Shanghai, China) between January 2008 and September 2008. None of the patients were pretreated with chemotherapy or radiotherapy prior to mastectomy. The patients whose specimens were used for immunohistochemical assays, were followed up for $\sim 8$ years (88-96 months) and their clinicopathological variables are summarized in Table I. Histological grading of primary breast cancer was evaluated according to the Nottingham grading system (11). Breast cancer subtypes were defined according to the St. Gallen Consensus 2013 (12). Written informed consent was obtained from all patients prior to surgery and the present study was approved by the Institutional Review Board of Shanghai Medical College at Fudan University (Shanghai, China).

$R T-q P C R$. Total RNA from 26 fresh breast cancer samples and corresponding adjacent non-cancerous breast tissues was extracted using TRIzol reagent (Invitrogen; Thermo Fisher Scientific, Inc., Waltham, MA, USA), according to the manufacturer's protocol. All RNA samples were then treated with 1 U/ $\mu 1$ RNase-free DNase (Promega Corporation, Madison, WI, USA) to eliminate genomic DNA. The concentration and quality of RNA was evaluated using the NanoDrop 2000 spectrophotometer (Thermo Fisher Scientific, Inc.). cDNA was then synthesized from $500 \mathrm{ng}$ total RNA using the PrimeScript RT Master Mix kit (Takara, Dalian, China). RT-qPCR was performed on the 7900HT Fast Real-Time PCR System (Applied Biosystems; Thermo Fisher Scientific, Inc.) using Power SYBR Green PCR Master mix (Applied Biosystems; Thermo Fisher Scientific, Inc.) to detect the expression level of EphA6, with GAPDH as a normalizing control. The primers for EphA6 and GAPDH, designed by Sangon Biotech Co., Ltd. (Shanghai, China), were as follows: EphA6 forward, 5'-TTGGAGAAGTCTGTAGTGGG-3' and reverse, 5'-CTT CTTTGCCGATCCATGTG-3'; and GAPDH forward, 5'-CTG ACTTCAACAGCGACACC-3' and reverse, 5'-TGCTGTAGC

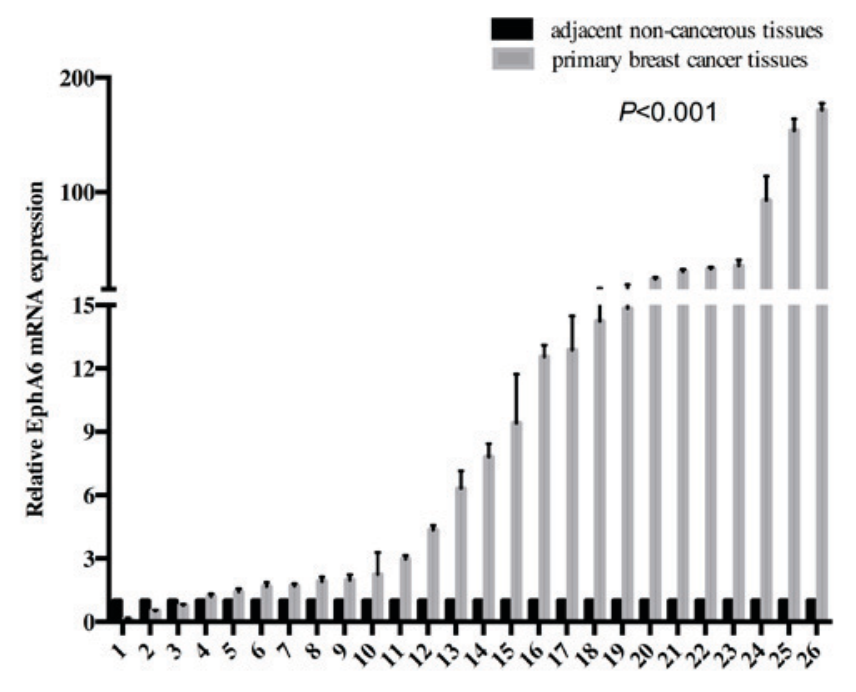

Figure 1. Relative EphA6 mRNA expression levels were increased in 26 breast cancer tissues compared with matched adjacent non-cancerous tissues, as determined by reverse transcription-quantitative polymerase chain reaction $(\mathrm{P}<0.001)$. EphA6, ephrin type-A receptor 6 .

CAAATTCGTTGT-3'. The thermocycling conditions were as follows: One cycle at $95^{\circ} \mathrm{C}$ for $10 \mathrm{~min}$, followed by 40 cycles of amplification at $95^{\circ} \mathrm{C}$ for $15 \mathrm{sec}$ and $60^{\circ} \mathrm{C}$ for $1 \mathrm{~min}$. The relative EphA6 mRNA expression of tumor and normal tissues was calculated using the following equations: $\Delta \mathrm{Cq}=\mathrm{Cq}$ (EphA6)-Cq (GAPDH); $\Delta \Delta \mathrm{Cq}=\Delta \mathrm{Cq}$ (tumor) $-\Delta \mathrm{Cq}$ (normal); fold change $=2^{-\Delta \Delta \mathrm{Cq}}(13)$.

IHC. Sections $(4 \mu \mathrm{m})$ were cut from FFPE specimens. Subsequent to baking for $2 \mathrm{~h}$ at $60^{\circ} \mathrm{C}$, the sections were dewaxed with xylene and rehydrated in a descending alcohol series (100, 95 and 70\%, successively). Endogenous peroxidase activity was blocked with $0.3 \%$ hydrogen peroxide for $30 \mathrm{~min}$ at $37^{\circ} \mathrm{C}$. For antigen retrieval, the sections were submerged in sodium citrate buffer $(\mathrm{pH} \mathrm{6.0)}$ at high pressure for $10 \mathrm{~min}$, and were then incubated with normal goat serum (dilution, 1:20) for $30 \mathrm{~min}$ at $37^{\circ} \mathrm{C}$ to reduce nonspecific binding. The sections were incubated with the rabbit anti-EphA6 polyclonal antibody (dilution, 1:50; catalog no. AP51189; Abgent Inc., San Diego, CA, USA) was used at a dilution of $1: 50$ overnight at $4^{\circ} \mathrm{C}$, followed by incubation with a poly-horseradish peroxidase (HRP) anti-mouse rabbit secondary antibody (Ready-To-Use; catalog no. D-3004-30; Shanghai Long Island Antibody Diagnostica Inc., Shanghai, China) for $45 \mathrm{~min}$ at $37^{\circ} \mathrm{C}$. Subsequent to rinsing, sections were stained with 3,3'-diaminobenzidine for $30 \mathrm{sec}$ at room temperature. Finally, in order to observe the nucleus, the sections were counterstained with hematoxylin for $1 \mathrm{~min}$ at room temperature, dehydrated with $70 \%$ alcohol and cleared with xylene.

Immunoreactivity was assessed with a confocal BX-51 microscope (Olympus America Inc., Melville, NY, USA; magnification, $\mathrm{x} 400$ ); results were evaluated separately by two independent pathologists (Professor Tang, Huashan Hospital, Shanghai, China and Professor Liu, The Fifth People's Hospital of Shanghai, China) who were blinded to the patient clinical information. The average scores provided 

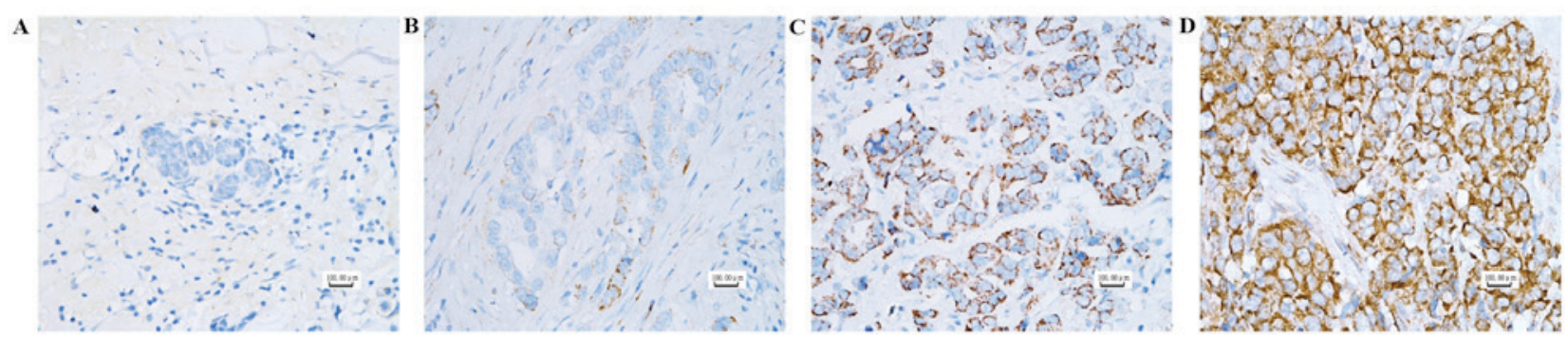

Figure 2. Expression of EphA6 protein, as determined by immunohistochemistry. (A) Negative staining of EphA6 in normal breast tissues. (B) Weak staining of EphA6 in breast cancer tissues. (C) Moderate staining of EphA6 in breast cancer tissues. (D) Strong staining of EphA6 in breast cancer tissues. Original magnification, $\mathrm{x} 400$; scale bars, $100 \mu \mathrm{m}$. EphA6, ephrin type-A receptor 6.
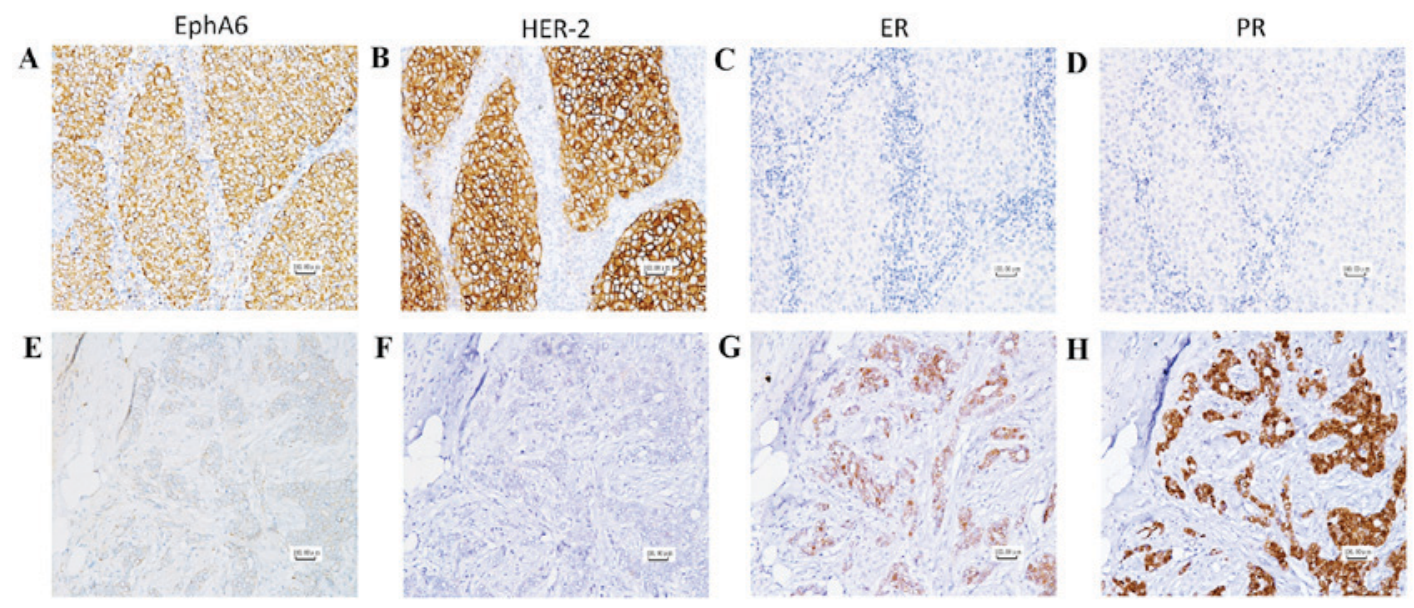

Figure 3. Serial sections of breast cancer tissue following immunohistochemical staining for ER, PR, HER-2 and EphA6. (A) Strong staining for EphA6 was accompanied by (B) positive staining for HER-2 and negative staining for (C) ER and (D) PR. (E) Weak staining for EphA6 was accompanied by (F) negative staining for HER-2 and positive staining for (G) ER and (H) PR. Original magnification, $\mathrm{x} 400$; scale bars, $100 \mu \mathrm{m}$. ER, estrogen receptor; PR, progesterone receptor; HER-2, human epidermal growth factor receptor 2; EphA6, ephrin type-A receptor 6.

by the two pathologists were used to evaluate EphA6 expression. The immunoreactivity score (IRS) was calculated using the following formula: IRS=staining intensity score ( 0 , no staining; 1 , weak staining; 2 , moderate staining; and 3 , strong staining) $\mathrm{x}$ percentage of positively stained tumor cells score $(0,0-5 ; 1,5-25 ; 2,25-50$; and 3, 50-100\%). Based on these scores, the expression levels of EphA6 were defined as high (IRS >4) or low (IRS $\leq 4)$ (14). Estrogen receptor (ER) and progesterone receptor (PR) expression was considered absent (nuclear staining in $<1 \%$ of tumor cells) or positive (nuclear staining in $\geq 1 \%$ of tumor cells) (15). For the common clinicopathological marker Ki-67, samples with $<14 \%$ positive nuclear-stained tumor cells were categorized as Ki-67 negative (16). HER-2 expression was scored as: 0 , no reactivity or membrane staining in $<10 \%$ of tumor cells; $1+$, faint/barely perceptible staining in $>10 \%$ of tumor cells; $2+$, weak to moderate membrane staining in $>10 \%$ of tumor cells; or $3+$, uniform intense membrane staining in $>10 \%$ of invasive tumor cells. Samples scored $2+$ were retested using fluorescence in situ hybridization (FISH). If the IHC score was 3+ or the FISH amplified ratio of HER-2 to CEP17 was $>2.2$, samples were considered positive for HER-2 (17).

Statistical analysis. Statistical analysis was performed using SPSS version 19.0 (SPSS, Inc., Chicago, IL, USA). Student's t-test was used to compare the differences in EphA6 expression between the cancerous and healthy breast tissues. The $\chi^{2}$ test was applied to investigate the association between EphA6 expression and clinicopathological characteristics. Overall survival (OS) was defined as the time period between the date of surgery and the date of mortality or final clinical follow-up. Survival curves were generated using the Kaplan-Meier method and comparisons were analyzed by the log-rank test. The Cox proportional hazards model was used for the univariate and multivariate analyses, and the adjusted hazard ratios and their $95 \%$ confidence intervals were calculated. $\mathrm{P}<0.05$ was considered to indicate a statistically significant difference.

\section{Results}

Upregulation of EphA6 $m R N A$ and protein expression in breast cancer tissues. EphA6 mRNA expression levels in the breast cancer tissues of 26 patients were significantly higher than that in the matched adjacent non-cancerous tissues, as determined by RT-qPCR analysis ( $\mathrm{P}<0.001$; Fig. 1). Additionally, IHC revealed that protein expression of EphA6 was absent in normal breast tissues and positive (weak-strong staining) in cancer tissues (Fig. 2). EphA6 staining was primarily observed in the cell cytoplasm and was present as coarse granules. In 
Table I. Association between EphA6 and clinicopathological characteristics.

\begin{tabular}{|c|c|c|c|c|}
\hline \multirow[b]{2}{*}{ Variable } & \multirow[b]{2}{*}{ Total, $\mathrm{n}$} & \multicolumn{2}{|c|}{ EphA6 expression, n (\%) } & \multirow[b]{2}{*}{ P-value } \\
\hline & & Low & High & \\
\hline All cases $(n=116)$ & 116 & $55(47.4)$ & $61(52.6)$ & \\
\hline Age & & & & 0.4511 \\
\hline$<50$ years & 59 & $30(50.8)$ & $29(49.2)$ & \\
\hline$\geq 50$ years & 57 & $25(43.9)$ & $32(56.1)$ & \\
\hline Tumor size & & & & 0.5793 \\
\hline$<2.5 \mathrm{~cm}$ & 88 & $43(48.9)$ & $45(51.1)$ & \\
\hline$\geq 2.5 \mathrm{~cm}$ & 28 & $12(42.9)$ & $16(57.1)$ & \\
\hline Lymph node metastasis & & & & 0.8525 \\
\hline Negative (-) & 58 & $28(48.3)$ & $30(51.7)$ & \\
\hline Positive (+) & 58 & $27(46.6)$ & $31(53.4)$ & \\
\hline TNM classification & & & & 0.7455 \\
\hline I & 46 & $21(45.7)$ & $25(54.3)$ & \\
\hline II & 53 & $27(50.9)$ & $26(49.1)$ & \\
\hline III & 17 & $7(41.2)$ & $10(58.8)$ & \\
\hline Histological grade & & & & $<0.001$ \\
\hline I (well) & 33 & $25(75.8)$ & $8(24.2)$ & \\
\hline II (moderate) & 52 & $21(40.4)$ & $31(59.6)$ & \\
\hline III (poor) & 31 & $9(29.0)$ & $22(71.0)$ & \\
\hline Estrogen receptor status & & & & 0.0247 \\
\hline Negative & 44 & $15(34.1)$ & $29(65.9)$ & \\
\hline Positive & 72 & $40(55.6)$ & $32(44.4)$ & \\
\hline Progesterone receptor status & & & & 0.0015 \\
\hline Negative & 56 & $18(32.1)$ & $38(67.9)$ & \\
\hline Positive & 60 & $37(61.7)$ & $23(38.3)$ & \\
\hline HER-2 status & & & & 0.0106 \\
\hline Negative & 77 & $43(55.8)$ & $34(44.2)$ & \\
\hline Positive & 39 & $12(30.8)$ & $27(69.2)$ & \\
\hline Ki-67 status & & & & 0.1145 \\
\hline Negative & 40 & $23(57.5)$ & $17(42.5)$ & \\
\hline Positive & 76 & $32(42.1)$ & $44(57.9)$ & \\
\hline p53 status & & & & 0.8974 \\
\hline Negative & 52 & $25(48.1)$ & $27(51.9)$ & \\
\hline Positive & 64 & $30(46.9)$ & $34(53.1)$ & \\
\hline Subtype & & & & 0.0164 \\
\hline Luminal A & 42 & $27(64.3)$ & $15(35.7)$ & \\
\hline Luminal B (HER-2-negative) & 12 & $6(50.0)$ & $6(50.0)$ & \\
\hline Luminal B (HER-2-positive) & 18 & $7(38.9)$ & $11(61.1)$ & \\
\hline HER-2 enriched & 21 & $4(19.0)$ & $17(81.0)$ & \\
\hline Basal-like (Triple negative) & 23 & $11(47.8)$ & $12(52.2)$ & \\
\hline Survival status & & & & 0.0141 \\
\hline Alive & 103 & $53(51.5)$ & $50(48.5)$ & \\
\hline Deceased & 13 & $2(15.4)$ & $11(84.6)$ & \\
\hline
\end{tabular}

EphA6, ephrin type-A receptor 6; TNM, Tumor-Node-Metastasis; erbB-2, receptor tyrosine-protein kinase erbB2; p53, tumor protein p53; HER-2, human epidermal growth factor 2. 
Table II. Univariate and multivariate analysis of prognostic indicators in breast cancer.

\begin{tabular}{|c|c|c|c|c|c|c|}
\hline \multirow[b]{2}{*}{ Variable } & \multicolumn{3}{|c|}{ Univariate analysis $(\mathrm{n}=116)$} & \multicolumn{3}{|c|}{ Multivariate analysis $(n=116)$} \\
\hline & HR & $95 \% \mathrm{CI}$ & P-value & HR & $95 \% \mathrm{CI}$ & P-value \\
\hline EphA6 expression & 5.296 & $1.174-23.897$ & 0.015 & 5.248 & $1.031-26.728$ & 0.046 \\
\hline Age & 0.294 & $0.081-1.069$ & 0.048 & 0.265 & $0.070-1.010$ & 0.052 \\
\hline Tumor size & 2.207 & $0.722-6.750$ & 0.154 & & & \\
\hline Lymph node metastasis & 1.158 & $0.389-3.447$ & 0.792 & & & \\
\hline TNM classification & 2.393 & $1.097-5.222$ & 0.024 & 2.974 & $1.350-6.553$ & 0.007 \\
\hline Histological grade & 2.295 & $1.030-5.118$ & 0.035 & 1.215 & $0.468-3.154$ & 0.690 \\
\hline ER & 0.356 & $0.116-1.088$ & 0.058 & & & \\
\hline PR & 0.390 & $0.120-1.267$ & 0.104 & & & \\
\hline HER-2 & 1.228 & $0.402-3.755$ & 0.718 & & & \\
\hline Ki-67 & 1.841 & $0.507-6.690$ & 0.346 & & & \\
\hline p53 & 1.299 & $0.425-3.972$ & 0.645 & & & \\
\hline Subtype & 1.540 & $1.049-2.262$ & 0.020 & 1.555 & $1.021-2.369$ & 0.040 \\
\hline
\end{tabular}

HR, hazard ratio; CI, confidence interval; EphA6, ephrin type-A receptor 6; TNM, Tumor-Node-Metastasis; ER, estrogen receptor; PR, progesterone receptor; HER-2, human epidermal growth factor-2; 553 , tumor protein $\mathrm{p} 53$.

A Overall survival rate of 116 cases

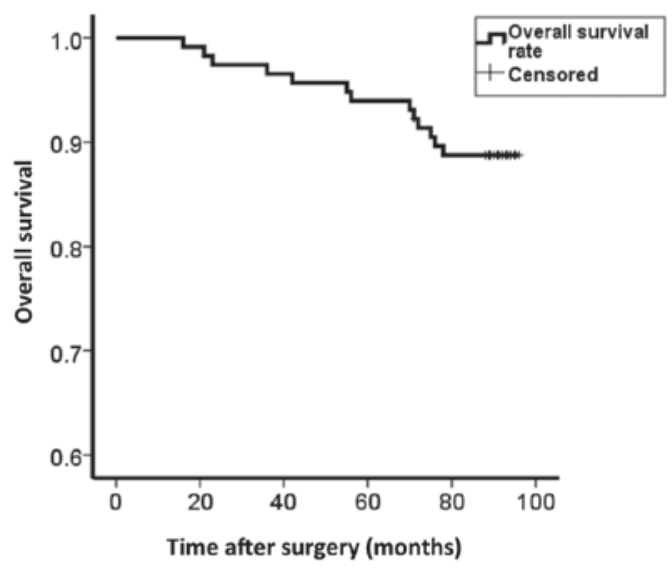

B Overall survival rate of different EphA6 expression

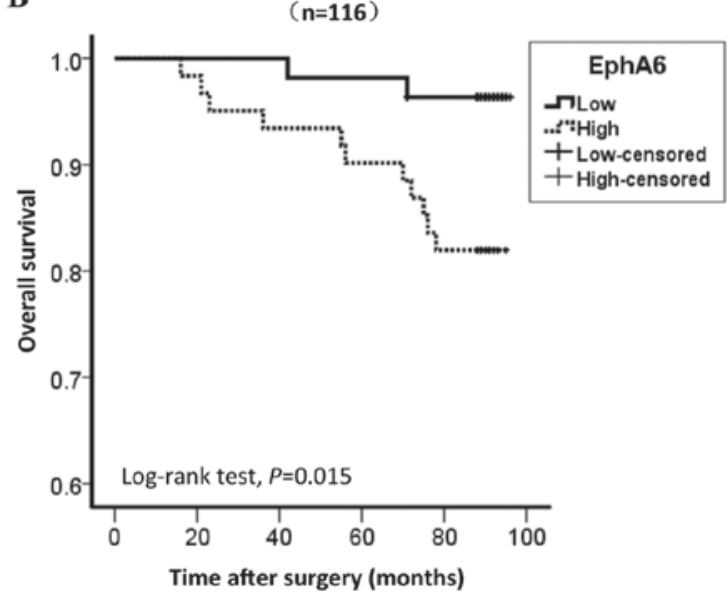

Figure 4. High EphA6 expression was associated with a poor survival rate of patients with breast cancer. (A) The overall survival rate of 116 patients with breast cancer. (B) Kaplan-Meier survival analysis of patients with breast cancer stratified by EphA6 expression level.

addition, EphA6 expression was positively associated with histological grade. As also demonstrated in Table I, more advanced histological grades were associated with a higher EphA6 expression.

Association between EphA6 expression and clinicopathological characteristics. To determine the significance of EphA6 in breast cancer, the association between the EphA6 expression in 116 patients with breast cancer and their clinicopathological characteristics was studied. As demonstrated in Table I, EphA6 expression was significantly positively associated with histological grade $(\mathrm{P}<0.001)$ and HER-2 overexpression $(\mathrm{P}=0.0106)$, but was significantly negatively associated with ER positivity $(\mathrm{P}=0.0247)$ and $\mathrm{PR}$ positivity $(\mathrm{P}=0.0015)$. The association between EphA6 and ER, PR and HER-2 expression is demonstrated in Fig. 3. The increased expression of EphA6 was also associated with breast cancer subtypes $(\mathrm{P}=0.0164)$. In the HER-2 enriched subtype, 17 out of 21 patients (81\%) exhibited the overexpression of EphA6 (Table I). However, no significant association was observed between EphA6 expression and other clinicopathological characteristics, including age, tumor size, lymph node metastasis, Tumor-Node-Metastasis (TNM) stage (18), or the status of the common clinicopathological markers, Ki-67 and tumor protein p53 ( $\mathrm{P}>0.05)$.

Prognostic significance of EPHA6 expression in breast cancer. The prognostic value of EphA6 expression was determined in 116 patients with breast cancer using Kaplan-Meier analysis and the log-rank test. The start time was between April 2008 to November 2008, and the end time was April 2016. At the end of the follow-up period 50/61 (82.0\%) patients with high EphA6 expression had survived, while 53/55 (96.4\%) patients 
with low EphA6 expression had survived. The OS rate of the 116 patients with breast cancer was $88.8 \%$ (Fig. 4A), and the OS rate of patients with high EphA6 expression was significantly lower than that of patients with low EphA6 expression $(\mathrm{P}=0.015$; Fig. 4B). As demonstrated in Table II, univariate analysis identified that OS was associated with EphA6 expression $(\mathrm{P}=0.015)$, age $(\mathrm{P}=0.048)$, TNM stage $(\mathrm{P}=0.024)$, histological grade $(\mathrm{P}=0.035)$ and breast cancer subtypes $(\mathrm{P}=0.020)$. Furthermore, Cox multivariate regression analysis demonstrated that EphA6 expression $(\mathrm{P}=0.046)$, TNM stage $(\mathrm{P}=0.007)$ and breast cancer subtypes $(\mathrm{P}=0.040)$ were independent prognostic factors for OS. These results indicated that the EphA6 expression level was significantly associated with the clinical prognosis of patients with breast cancer.

\section{Discussion}

EphA6, a member of the Eph receptor family, is widely expressed in human healthy tissues with organ-specific patterns. A previous study demonstrated that EphA6 was downregulated in colorectal carcinoma and renal cell carcinoma (19), whereas the role of EphA6 in tumorigenesis and its potential molecular mechanisms have not yet been investigated. In a previous study, Li et al (10) demonstrated that overexpression of EphA6 contributed to human prostate cancer progression. However, to the best of our knowledge, the function and prognostic significance of EphA6 in human breast cancer has not been previously investigated.

Breast cancer is a heterogeneous disease with a wide range of potential clinical outcomes, pathological entities and molecular features. Based on the status of ER, PR and HER-2, the St. Gallen Consensus formulated 4 subtypes of breast cancer: Luminal A; luminal B; HER-2-overexpressing; and triple negative breast cancer. These subclasses have prognostic value across multiple targeted therapy settings (20).

In the present study, EphA6 mRNA and protein expression were significantly upregulated in breast cancer tissues compared with matched adjacent non-cancerous tissues $(\mathrm{P}<0.001)$. In addition, IHC analysis of 116 FFPE breast cancer specimens revealed that EphA6 expression was significantly associated with histological grade $(\mathrm{P}<0.001), \mathrm{ER}(\mathrm{P}=0.0247)$, $\mathrm{PR}(\mathrm{P}=0.0015)$ and HER-2 $(\mathrm{P}=0.0106)$ status and breast cancer subtypes $(\mathrm{P}=0.0164)$. High EphA6 expression was more likely to occur in ER (-), PR (-), HER-2 (+) or HER-2-overexpressing subtypes of breast cancer, or those with a high histological grade. Therefore, the HER-2 overexpression subtypes were defined as ER-negative, PR-negative and HER2-positive. In addition, overexpression of EphA6 in patients with breast cancer was markedly associated with a poor survival rate. Univariate and multivariate analysis indicated that high EphA6 expression level was an independent prognostic indicator for patients with breast cancer $(\mathrm{P}=0.015$ and $\mathrm{P}=0.046$, respectively).

ER and HER-2 are predictive markers for associated targeted therapies (21). Patients with ER-positive breast cancer are generally advised to undergo adjuvant endocrine therapy, which may decrease the recurrence and mortality rates (22). The amplification of HER-2 has been observed in $\leq 20 \%$ of breast cancers (23), and overexpression of HER-2 has been reported to be associated with a poor prognosis, a high frequency of recurrence and a reduced OS rate (24). Herceptin is a humanized monoclonal antibody that targets HER-2 and enhances its response to chemotherapeutic agents (25). As with HER-2, EphA6 also belongs to the receptor tyrosine kinase family, suggesting that EphA6 may also be a possible alternative target site for monoclonal antibody therapy. In addition, there is crosstalk between the ER and HER family signaling pathways, which contributes to the resistance to endocrine therapies against the ER pathway (26). Therefore, a reciprocal inhibition may exist in steroid receptor and growth factor receptor signaling, in accordance with the observations that EphA6 expression is positively associated with HER-2 expression and negatively associated with ER and PR expression.

Eph family members may generate a bidirectional signal by binding to cell surface-associated ephrin ligands. As one of the most studied members of the Eph family, EphA2 overexpression was revealed to be inversely associated with hormone receptor (ER and PR) expression in endometrial carcinomas (27) and significantly associated with the poor prognosis of HER-2 overexpressing patients with breast cancer (28), which was similar to the results for EphA6 in the present study. In addition, an increasing volume of evidence has suggested that the EPHA2-ephrin-A1 system serves a crucial role in tumorigenesis and vascularization during carcinogenesis (8). Therefore, these results indicated EphA6 may also function by interacting with ephrin-A1 or other ephrins.

In conclusion, to the best of our knowledge, the present study is the first to report the expression and clinical relevance of EphA6 in breast cancer. EphA6 overexpression was revealed to be associated with indicators of a poor prognosis, including high histological grades, low expression of steroid hormone receptors and amplification of HER-2. The results of the present study also demonstrated that high expression of EphA6 was more prevalent in HER-2-enriched breast cancer than in other phenotypes. Furthermore, EphA6 overexpression was identified to be an important independent prognostic indicator in breast cancer. In an era of high precision medicine, EphA6 may be a useful therapeutic target, particularly in patients with breast cancer that exhibit HER-2 overexpression and lack the steroid receptor. However, the underlying mechanisms of the activity of EphA6 in breast cancer remain unknown and additional studies are required to improve the understanding of its molecular mechanisms.

\section{References}

1. Ferlay J, Soerjomataram I, Dikshit R, Eser S, Mathers C, Rebelo M, Parkin DM, Forman D and Bray F: Cancer incidence and mortality worldwide: Sources, methods and major patterns in GLOBOCAN 2012. Int J Cancer 136: E359-E386, 2014.

2. Fan L, Strasser-Weippl K, Li JJ, St Louis J, Finkelstein DM, Yu KD, Chen WQ, Shao ZM and Goss PE: Breast cancer in China. Lancet Oncol 15: e279-e289, 2014.

3. Bernier J, Rossier C and Horiot JC: Recent advances in regional treatment of breast carcinoma. Crit Rev Oncol Hemato 99: 107-114, 2016.

4. Partridge AH: Chemotherapy in premenopausal breast cancer patients. Breast Care (Basel) 10: 307-310, 2015.

5. Rakha EA: Pitfalls in outcome prediction of breast cancer. J Clin Pathol 66: 458-464, 2013.

6. Hirai H, Maru Y, Hagiwara K, Nishida J and Takaku F: A novel putative tyrosine kinase receptor encoded by the eph gene. Science 238: 1717-1720, 1987.

7. Pasquale EB: Eph-ephrin bidirectional signaling in physiology and disease. Cell 133: 38-52, 2008. 
8. Pasquale EB: Eph receptors and ephrins in cancer: Bidirectional signalling and beyond. Nat Rev Cancer 10: 165-180, 2010.

9. Pasquale EB: Eph receptor signalling casts a wide net on cell behaviour. Nat Rev Mol Cell Biol 6: 462-475, 2005.

10. Li S, Ma Y, Xie C, Wu Z, Kang Z, Fang Z, Su B and Guan M: EphA6 promotes angiogenesis and prostate cancer metastasis and is associated with human prostate cancer progression. Oncotarget 6: 22587-22597, 2015.

11. Elston CW and Ellis IO: Pathological prognostic factors in breast cancer. I. The value of histological grade in breast cancer: Experience from a large study with long-term follow-up. Histopathology 19: 403-410, 1991.

12. Untch M, Gerber B, Harbeck N, Jackisch C, Marschner N, Möbus V, von Minckwitz G, Loibl S, Beckmann MW, Blohmer JU, et al: 13th st. Gallen international breast cancer conference 2013: primary therapy of early breast cancer evidence, controversies, consensus-opinion of a german team of experts (zurich 2013). Breast Care (Basel) 8: 221-229, 2013.

13. Livak KJ and Schmittgen TD: Analysis of relative gene expression data using real-time quantitative PCR and the 2(-Delta Delta C(T)) method. Methods 25: 402-408, 2001.

14. You Y, Li H, Qin X, Ran Y and Wang F: Down-regulated ECRG4 expression in breast cancer and its correlation with tumor progression and poor prognosis-A short report. Cell Oncol (Dordr) 39: 89-95, 2016

15. Parl FF, Schmidt BP, Dupont WD and Wagner RK: Prognostic significance of estrogen receptor status in breast cancer in relation to tumor stage, axillary node metastasis, and histopathologic grading. Cancer 54: 2237-2242, 1984

16. Howell SJ, Wardley AM and Armstrong AC: Re: Ki67 index, HER2 status, and prognosis of patients with luminal B breast cancer. J Natl Cancer Inst 101: 1730-1731, 2009.

17. Wolff AC, Hammond ME, Schwartz JN, Hagerty KL, Allred DC, Cote RJ, Dowsett M, Fitzgibbons PL, Hanna WM, Langer A, et al: American society of clinical oncology/college of American pathologists guideline recommendations for human epidermal growth factor receptor 2 testing in breast cancer. J Clin Oncol 25: 118-145, 2007.

18. Edge SB and Compton CC: The American joint committee on cancer: The 7th edition of the AJCC cancer staging manual and the future of TNM. Ann Surg Oncol 17: 1471-1474, 2010.
19. Hafner C, Schmitz G, Meyer S, Bataille F, Hau P, Langmann T, Dietmaier W, Landthaler M and Vogt T: Differential gene expression of Eph receptors and ephrins in benign human tissues and cancers. Clin Chem 50: 490-499, 2004.

20. Rouzier R, Perou CM, Symmans WF, Ibrahim N, Cristofanilli M, Anderson K, Hess KR, Stec J, Ayers M, Wagner P, et al: Breast cancer molecular subtypes respond differently to preoperative chemotherapy. Clin Cancer Res 11: 5678-5685, 2005.

21. Kourea HP, Zolota V and Scopa CD: Targeted pathways in breast cancer: Molecular and protein markers guiding therapeutic decisions. Curr Mol Pharmacol 7: 4-21, 2014.

22. Payne SJ, Bowen RL, Jones JL and Wells CA: Predictive markers in breast cancer-the present. Histopathology 52: 82-90, 2008.

23. Gajria D and Chandarlapaty S: HER2-amplified breast cancer: Mechanisms of trastuzumab resistance and novel targeted therapies. Expert Rev Anticancer Ther 11: 263-275, 2011.

24. English DP, Roque DM and Santin AD: HER2 expression beyond breast cancer: Therapeutic implications for gynecologic malignancies. Mol Diagn Ther 17: 85-99, 2013.

25. Pietras RJ, Pegram MD, Finn RS, Maneval DA and Slamon DJ: Remission of human breast cancer xenografts on therapy with humanized monoclonal antibody to HER-2 receptor and DNA-reactive drugs. Oncogene 17: 2235-2249, 1998.

26. Arpino G, Wiechmann L, Osborne CK and Schiff R: Crosstalk between the estrogen receptor and the HER tyrosine kinase receptor family: Molecular mechanism and clinical implications for endocrine therapy resistance. Endocr Rev 29: 217-233, 2008.

27. Kamat AA, Coffey D, Merritt WM, Nugent E, Urbauer D, Lin YG, Edwards C, Broaddus R, Coleman RL and Sood AK: EphA2 overexpression is associated with lack of hormone receptor expression and poor outcome in endometrial cancer. Cancer 115: 2684-2692, 2009.

28. Zhuang G, Brantley-Sieders DM, Vaught D, Yu J, Xie L, Wells S, Jackson D, Muraoka-Cook R, Arteaga C and Chen J: Elevation of receptor tyrosine kinase EphA2 mediates resistance to trastuzumab therapy. Cancer Res 70: 299-308, 2010 